\title{
ABO BLOOD GROUP SYSTEM AND CARCINOMA STOMACH- A RETROSPECTIVE STUDY IN A TERTIARY CARE CENTRE
}

\author{
B. Suresh Kumar1, D. Loganathan², A. Mohammed Imran Khan ${ }^{3}$
}

${ }_{1}^{1}$ Assistant Professor, Department of General Surgery, Government Vellore Medical College and Hospital.

2 Professor, Department of General Surgery, Government Vellore Medical College and Hospital.

3Junior Resident, Department of General Surgery, Government Vellore Medical College and Hospital.

\section{ABSTRACT}

\section{BACKGROUND}

Objective of this study is to establish and determine the relationship between the ABO blood group association with Carcinoma Stomach.

\section{MATERIALS AND METHODS}

This is a retrospective study conducted in Tertiary Care Centre, Government Vellore Medical College Hospital to compare association of blood grouping with Carcinoma Stomach. Study period was from January 2011 to January 2016. Sixty three (63) male patients were enrolled in the study. And data was collected based on Age wise and Blood group wise distribution of Carcinoma Stomach.

\section{RESULTS}

63 cases of Carcinoma Stomach were studied-

1. Carcinoma stomach was more common in the non-blood group 0.

2. Among the non-blood group $\mathrm{O}$ it was more common in Blood group $\mathrm{A}$.

3. Carcinoma Stomach was less common in patients with blood group 0.

4. The incidence of Carcinoma stomach was highest in the age group of 50 - 60 years.

5. Highest incidence of Carcinoma stomach seen in Rh Positive Individuals (56 patients).

\section{CONCLUSION}

In conclusion, our study confirmed that Carcinoma Stomach risk is increased in Patients with blood group A, as compared to those in non-A blood groups. Patients with blood group 0 showed a significant reduced risk of Carcinoma Stomach compared with non-O blood groups. The susceptibility of blood group A Patients to Carcinoma Stomach may be partially attributed to an increased risk of H. pylori infection. This study implied that there must be a host genetic susceptibility for gastric cancer. However, the exact molecular mechanism underlying the relationship between $\mathrm{ABO}$ blood groups, H. pylori infection and gastric cancer needs to be further explored.

\section{KEYWORDS}

Gastric Cancer, ABO Blood Group, Gastric Perforation.

HOW TO CITE THIS ARTICLE: Kumar BS, Loganathan D, Khan AMI. ABO blood group system and carcinoma stomach- A retrospective study in a tertiary care centre. J. Evolution Med. Dent. Sci. 2017;6(6):452-454, DOI: 10.14260/Jemds/2017/99

\section{BACKGROUND}

Gastric Cancer is the 2nd most common cancer worldwide. There are about 1 million cases diagnosed each year. There are about 70,000 deaths occurring due to Gastric cancer in the World. There are various risk factors that are associated with Gastric Cancer. For a long time, there have been efforts to establish association of ABO blood grouping with Gastric cancer in order to establish which Blood group individuals are more susceptible to Gastric cancer. This study was done to study the same in our Hospital in biopsy proven Carcinoma Stomach patients.

Financial or Other, Competing Interest: None.

Submission 13-12-2016, Peer Review 06-01-2017,

Acceptance 12-01-2016, Published 19-01-2017.

Corresponding Author:

Dr. B. Suresh Kumar,

Assistant Professor,

Department of General Surgery,

Government Vellore Medical College and Hospital.

E-mail: drsureshb@yahoo.com

DOI: $10.14260 /$ jemds $/ 2017 / 99$

\section{MATERIALS AND METHODS}

This study is a retrospective study done by analysing the data from Medical Records Department in Patients with carcinoma stomach during the time period from January 2011 to January 2016 in Government Vellore Medical College and Hospital About 63 patients with Carcinoma Stomach were analysed retrospectively. The data were also analysed with the blood bank of the Hospital.

\section{The Data was Categorised into Two Groups-}

1. Blood group wise distribution of Carcinoma stomach.

2. Age wise distribution of carcinoma stomach.

In this study, Patients who were diagnosed as Carcinoma Stomach by upper GI endoscopic biopsy were analysed for their blood group association. All the patients were not admitted in General Surgery Ward with admissions also in palliative care ward, Intensive care unit and some cases were referred to higher centre after admission. The grades of Carcinoma and the site at which Cancer occurred are not analysed. 
The numbers of patients for whom data have been collected and the sources of the material are shown in Table 1 and table 2 .

\section{RESULTS}

The retrospective study of 63 patients with carcinoma stomach and their association of blood grouping with it showed that most cancers have occurred in patients with Blood group A and the least association is in patients with Blood group 0.

The table 1 shows most of the Gastric Cancer occurred in patients in thirty-eight patients $(60.3 \%)$ with blood group A followed by blood group $B(15.8 \%)$ and blood group $A B$ (15.8\%) and blood group 0 (7.9\%).

Table 2 depicts age of the patients ranged from 20 to 80 years. The highest incidence of Carcinoma Stomach was highest in the age group of 40-60 years (55.55\%) followed by $60-80$ years $(39.68 \%)$ and in $20-40$ years $(4.76 \%)$. The middle-aged population of 40- 60 years constitutes majority population. Most of the patients belong to the lower socioeconomic group and were illiterate or semiliterate.

Table 3 depicts association $\mathrm{Rh}$ with Carcinoma Stomach. The highest incidence of Carcinoma stomach occurred in Positive group 56 individuals (88.88\%).

\begin{tabular}{|c|c|}
\hline Blood Group & Carcinoma Stomach \\
\hline A & 38 \\
\hline B & 10 \\
\hline O & 5 \\
\hline AB & 10 \\
\hline Table 1. Blood group wise distribution of Carcinoma \\
Stomach \\
\hline
\end{tabular}

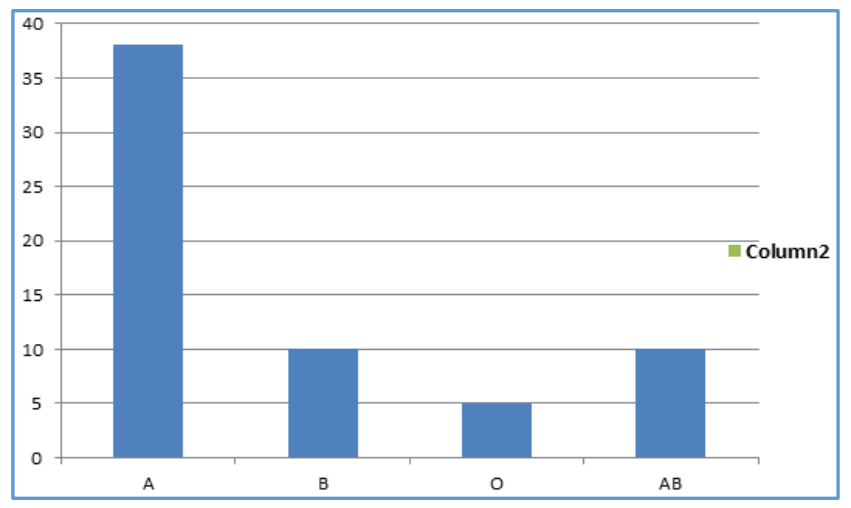

Figure 1. Blood Group wise Distribution of Carcinoma Stomach

\begin{tabular}{|c|c|}
\hline Age Group & Carcinoma Stomach \\
\hline$<20$ YRS. & 0 \\
\hline $20-40$ YRS. & 3 \\
\hline $40-60$ YRS. & 35 \\
\hline >60 YRS. & 25 \\
\hline Table 2. Age wise distribution of Duodenal and Gastric \\
Perforation \\
\hline
\end{tabular}

\section{CARCINOMA STOMACH - AGE}

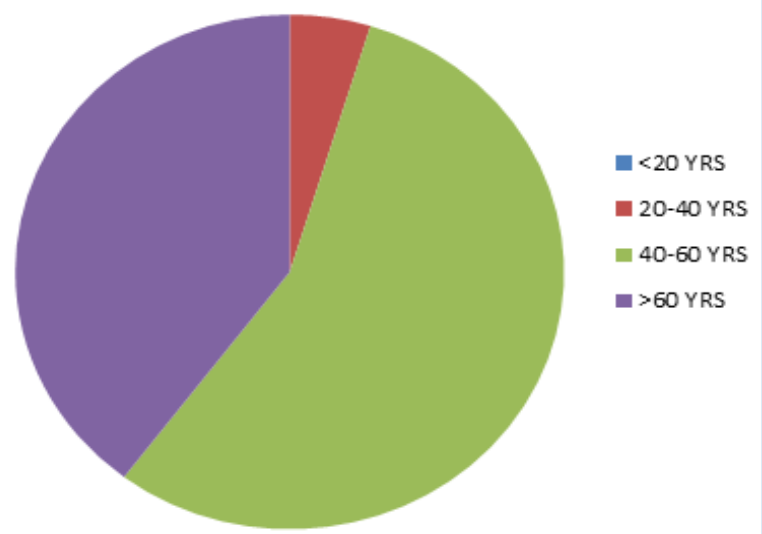

Figure 2. Age wise distribution of Carcinoma Stomach

\begin{tabular}{|c|c|}
\hline Rh & Carcinoma Stomach \\
\hline Positive & 56 \\
\hline Negative & 9 \\
\hline Table 3. Rh association with Carcinoma Stomach \\
\hline
\end{tabular}

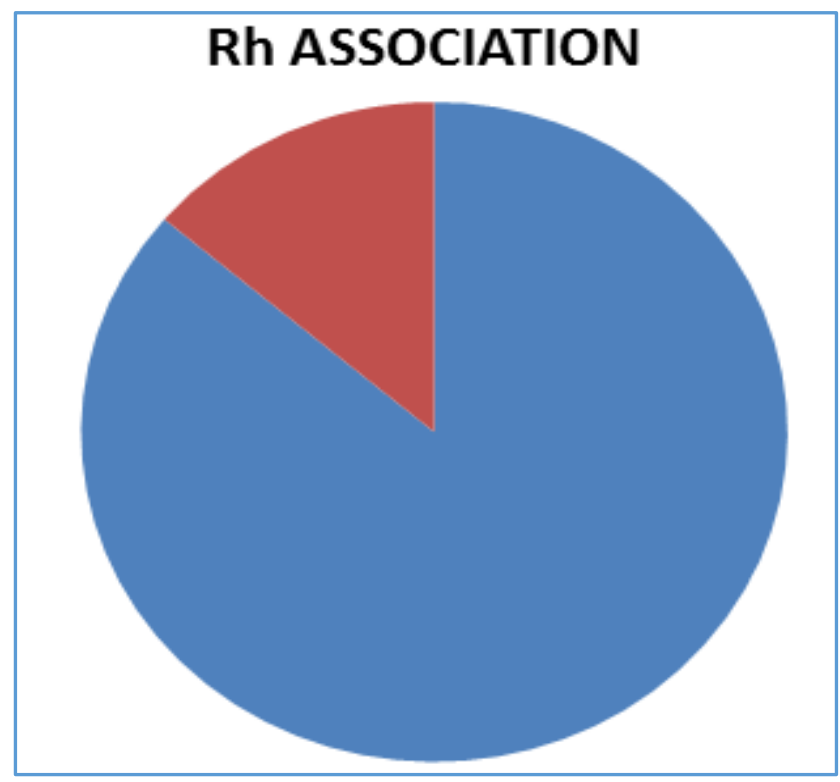

\section{DISCUSSION}

The relationship between blood groups and incidence of Carcinoma was done for many years. It was done in various other carcinomas like Pancreatic cancers. But there were no established studies as far as Stomach pathology is concerned until Alexander proposed the relationship between blood group 0 and peptic ulcer in $1921 .^{1}$

The association of blood group A and Carcinoma Stomach has been mentioned in studies of various groups. ${ }^{2}$ In regards to the possible explanations for the increased incidence of gastric cancer in blood group A individuals, Roberts et al proposed that individuals with blood group A were more susceptible to pernicious anaemia, compared with non-A blood group individuals. ${ }^{3} \mathrm{~A}$ pernicious anaemia individual is more prone to gastric cancer. A clinical study demonstrated that altered gastric secretary function may be related to the ABO blood group. Compared to individuals with blood group $\mathrm{A}$, the individuals of blood group $\mathrm{O}$ produced more free acid 
in their stomachs. The mean value of plasma pepsinogen in individuals with blood group 0 (564 units/mL) was higher than that in individuals with blood group A (494 units $/ \mathrm{mL}$ ). ${ }^{4}$ One study indicated that the immune-reaction to tumours in individuals with blood group A was reduced compared with the non-A blood group individuals. ${ }^{5}$ This discovery suggested that individuals with the A blood group antigen may be more susceptible to H. pylori invasion. 5

Recently, one paper published in Nature journal indicated that the erythrocyte receptor-ligand pair is essential for erythrocyte invasion in the pathogenesis of malaria. They found that Ok blood group antigen, a kind of blood group antigen, is a receptor for erythrocyte invasion of the parasite. ${ }^{6}$ This discovery suggested that individuals with the A blood group antigen may be more susceptible to $\mathrm{H}$. Pylori invasion. Therefore, we further analysed the infection status in our gastric cancer cohort and found that the ratio of $\mathrm{H}$. pylori infection in blood group A cases was significantly higher than that in non-A blood group cases.

Recently, Nakao et al analysed the ABO genotype and the risk of gastric cancer, atrophic gastritis and $\mathrm{H}$. pylori infection, and proposed that the risk for gastric cancer, atrophic gastritis and $\mathrm{H}$. pylori infection was increased in AA genotype. ${ }^{7}$ This finding is consistent with our data. H. pylori plays an important role in the development of gastric ulcer and gastric cancer.

H. pylori is a Gram-negative bacterium, which can be divided into cytotoxin-associated antigen (CagA) and vacuolating cytotoxin (VacA) positive strains, as well as CagA and VacA negative strains. ${ }^{8}$ CagA positive $\mathrm{H}$. Pylori suggest a considerably increased risk of gastric cancer. ${ }^{9}$ The adhesion molecule system of $\mathrm{H}$. pylori helps the bacteria colonising in stomach mucosa. The most important adhesion molecule is blood group antigen-binding adhesion A (BabA). Adherence by $\mathrm{H}$. pylori increases the risk of gastric disease.

Animal experiments revealed that BabA could stimulate the inflammatory cells to release more interleukin-8, CCL5 proinflammatory cytokines and precancer-related factors (CDX2 and MUC2). ${ }^{10}$ Since inflammatory response to H. Pylori infection plays an important role in cellular proliferation and gastric mucosal damage, the upregulation of proinflammatory cytokines in people with chronic gastritis may be an important clinical implication in gastric carcinogenesis. ${ }^{11}$

\section{CONCLUSION}

Our study confirmed that Carcinoma Stomach risk is increased in Patients with blood group A, as compared to those in non-A blood groups. Patients with blood group 0 showed a significant reduced risk of Carcinoma Stomach compared with non-O blood groups. The susceptibility of blood group A Patients to Carcinoma Stomach may be partially attributed to an increased risk of H. pylori infection. This study implied that there must be a host genetic susceptibility for gastric cancer. However, the exact molecular mechanism underlying the relationship between ABO blood groups, $\mathrm{H}$. pylori infection and gastric cancer needs to be further explored.

63 Cases of Carcinoma Stomach were studied-

1. Carcinoma stomach was more common in the nonblood group 0 .

2. Among the non-blood group $\mathrm{O}$ it was more common in Blood group A.

3. 3Carcinoma Stomach was less common in patients with blood group 0 .

4. The incidence of Carcinoma stomach was highest in the age group of 50 - 60 years.

5. Highest incidence of Carcinoma stomach seen in $\mathrm{Rh}$ Positive Individuals (56 patients).

\section{REFERENCES}

[1] Aird I, Bentall HH, Roberts JA. A relationship between cancer of stomach and the ABO blood groups. Br Med J 1953;1(4814):799-801.

[2] Hems G. Epidemiological characteristics of breast cancer in middle and late age. $\mathrm{Br} \mathrm{J}$ Cancer 1970;24(2):226-34.

[3] Vioque J, Walker AM. Pancreatic cancer and ABO blood types: a study of cases and controls. Med Clin 1991;96(20):761-4.

[4] Henderson J, Seagroatt V, Goldacre M. Ovarian cancer and ABO blood groups. J Epidemiol Community Health 1993;47(4):287-9.

[5] Beasley WH. Blood groups of gastric ulcer and carcinoma. Br Med J 1960;1(5180):1167-72.

[6] Roberts JA. Some associations between blood groups and disease. Br Med Bull 1959;15(2):129-33.

[7] Wiener AS. Blood-groups and disease. A critical review. Lancet 1962;1(7234):813-6.

[8] Casas JP, Hingorani AD, Bautista LE, et al. Meta-analysis of genetic studies in ischemic stroke: thirty-two genes involving approximately 18,000 cases and 58,000 controls. Arch Neurol 2004;61(11):1652-61.

[9] Banerjee I, Gupta V, Ganesh S. Association of gene polymorphism with genetic susceptibility to stroke in Asian populations: a meta-analysis. J Hum Genet 2007;52(3):205-19.

[10] Hoskins LC, Loux HA, Britten A, et al. Distribution of ABO blood groups in patients with pernicious anemia, gastric carcinoma and gastric carcinoma associated with pernicious anemia. $\mathrm{N}$ Engl J Med 1965;273(12):633-7.

[11] Viera AJ. Odds ratios and risk ratios: what's the difference and why does it matter? South Med J 2008;101(7):730-4. 